\title{
Microwave Absorption of Crystalline Fe/MnO@C Nanocapsules Embedded in Amorphous Carbon
}

Cite as

Nano-Micro Lett.

(2020) 12:57

Received: 14 November 2019

Accepted: 8 January 2020

Published online: 18 February 2020

(C) The Author(s) 2020

\author{
Gaihua $\mathrm{He}^{1}$, Yuping Duan ${ }^{1}$, Huifang Pang ${ }^{1}$ \\ $\checkmark$ Yuping Duan, duanyp@dlut.edu.cn \\ 1 Key Laboratory of Solidification Control and Digital Preparation Technology (Liaoning Province), \\ School of Materials Science and Engineering, Dalian University of Technology, Dalian 116085, \\ People's Republic of China
}

\section{HIGHLIGHTS}

- The crystalline Fe/MnO@C core-shell nanocapsules embedded in porous amorphous carbon matrix (FMCA) was prepared by a novel confinement strategy of modified arc-discharge method.

- The heterogeneous crystalline-amorphous nanocrystals disperse evenly and exhibit improvement of static magnetization and excellent electromagnetic absorption properties.

- The adding $\mathrm{MnO}_{2}$ confines degree of graphitization and contributes to form amorphous carbon. Dielectric loss and microwave absorption are achieved adjustable.

ABSTRACT Crystalline Fe/MnO@C core-shell nanocapsules inlaid in porous amorphous carbon matrix (FMCA) was synthesized successfully with a novel confinement strategy. The heterogeneous Fe/ $\mathrm{MnO}$ nanocrystals are with approximate single-domain size which gives rise to natural resonance in $2-18 \mathrm{GHz}$. The addition of $\mathrm{MnO}_{2}$ confines degree of graphitization catalyzed by iron and contributes to the formation of amorphous carbon. The heterogeneous materials composed of crystalline-amorphous structures disperse evenly and its density is significantly reduced on account of porous properties. Meanwhile, adjustable dielectric loss is achieved by interrupting Fe core aggregation and stacking graphene conductive network. The dielectric loss synergistically with magnetic loss endows the FMCA enhanced absorption. The optimal reflection loss (RL) is up to $-45 \mathrm{~dB}$, and the effective bandwidth $(\mathrm{RL}<-10 \mathrm{~dB})$ is $5.0 \mathrm{GHz}$ with $2.0 \mathrm{~mm}$ thickness. The proposed confinement strategy not only lays the foundation for designing high-performance microwave absorber, but also offers a

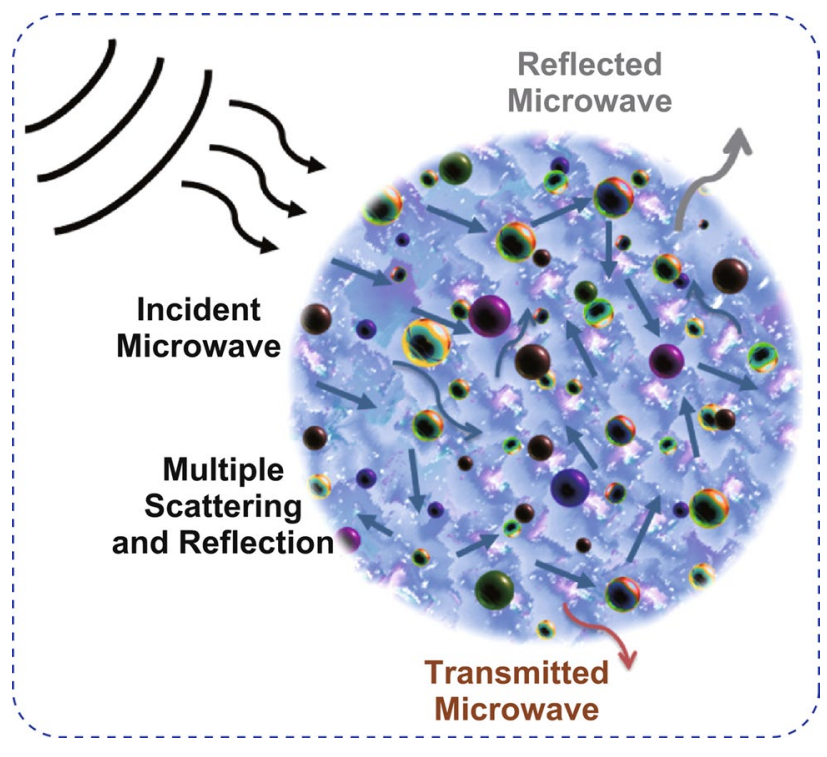
general duty synthesis method for heterogeneous crystalline-amorphous composites with tunable composition in other fields.

KEYWORDS Crystalline nanocapsule; Amorphous carbon; Core-shell structure; Interfacial polarization; Microwave absorption 


\section{Introduction}

As science and technology develop dramatically fast, electromagnetic radiation pollution has become a growing problem due to the explosive growth in the application of electronic devices, such as radar systems, local area networks, telephones, and computers. Overexposure to electromagnetic wave can not only affect the functioning of electronic equipment but also be potentially detrimental to human being and raise severe problems concerning the field of military applications [1-3]. Therefore, it has spurred internationally unprecedented interest in exploring microwave absorbing materials, which converts electromagnetic wave into energy in other forms [4, 5]. For practical applications, desirable microwave absorbing materials are supposed to possess key features of high absorptive capacity, broad effective bandwidth, light weight, and low filler loading ratio [6-8]. Thus, it is urgent to develop materials with satisfaction of these conditions simultaneously.

Soft magnetic metal and alloys (i.e., $\mathrm{Fe}, \mathrm{Co}, \mathrm{Ni}$, and their alloys) have been extensively applied for electromagnetic wave-absorbing materials because of their strong ferromagnetic properties, widely magnetic anisotropy, and popular domain wall displacement [9-11]. Nevertheless, the Snoek's limit, poor impedance matching, large density, easy oxidation, and magnetic aggregation restrict their electromagnetic wave absorption property. In order to overcome these problems and further improve their microwave absorption properties, the magnetic materials are usually recombined with different dielectric materials, which is on base of the synergy of magnetic and dielectric mechanisms. Among plenty of dielectric loss medium, carbon materials are superior in the field of microwave absorption in virtue of their special merits, such as chemical stability, tunable physical and chemical properties, and various forms [7, 12-26]. Specially, massive efforts have been devoted continuously to developing absorbers, constituting carbon materials and magnetic metal iron composition recently. In past, the multicomponent hybrids Fe@C nanocapsules [27], Fe-C nanofibers [28], graphene-coated Fe nanoparticles [29], Fe@ C microspheres [1], mesoporous $\mathrm{Fe} / \mathrm{C}$ composition [30], $\mathrm{C} @ \mathrm{Fe}_{2} \mathrm{O}_{3} / \mathrm{Fe}_{3} \mathrm{C} /$ $\mathrm{Fe}-\mathrm{CNT}$ nanoparticle decorated carbon nanotubes [31] display good electromagnetic absorption capabilities and wide effective frequency range to some extent.
Despite the promising progresses aforementioned, great problems remain to be resolved. At first, it is rather challenging and still imperative to tune the magnetic nanoparticles size and distribution by rational design and construction of architectures of microwave absorption materials to solve the problem of random distribution and serious aggregation. Second, carbon-magnetic composite possesses overhigh electrical conductivity owing to the laminated carbon structure, which results in the occurrence of significant skin effects under electromagnetic wave. Third, $\mathrm{Fe}_{3} \mathrm{C}$ is always inescapable accompanied by reaction. More importantly, the magnetic dilution will generate due to the introduction of nonmagnetic dielectric components.

It is inspired from researches to fabricate crystalline-amorphous composition comprised amorphous matrix and dispersed nanocrystalline $[2,32,33]$, in which the unique construction conduces to the uniform dispersion of the magnetic nanoparticles, shows a high density interfaces and significant interfacial polarizations, benefiting for microwave attenuation. Hence, it is promising to find a simple method to construct heterogeneous material composed of crystalline-amorphous structure. One feasible approach is introduction of transition metal oxide $\mathrm{MnO}$ to construct heterogeneous crystalline-amorphous $\mathrm{Fe}-\mathrm{C}$-based composition with nanoscale architectures and further boost microwave absorption performance. The $\mathrm{MnO}$ in size of nanoscale contributes to produce more dipoles and dipolar relaxation [34]. $\mathrm{MnO}$ dispersed on the surface of graphene can also weaken the $\pi-\pi$ stacking interactions [35]. Otherwise, introducing $\mathrm{MnO}$ increases the heterostructure among $\mathrm{MnO}, \mathrm{Fe}$, and carbon, which can result in unpaired spins, form plentiful magnetic moments and further induce magnetic ordering in materials [36].

Herein, a kind of crystalline Fe/MnO@C core-shell nanocapsules inlaid in porous amorphous carbon was successfully prepared by arc-discharge method, which generates abundant interfaces because of graphitized graphene and amorphous carbon. The layer of graphene and size of dispersive $\mathrm{Fe} / \mathrm{MnO}$ nanocrystal can be tuned by introduction content of $\mathrm{MnO}$. And the magnetic dilution is compensated via enhanced surface anisotropy and resonance where Fe nanoparticles are confined about single-domain size. The novel configuration of $\mathrm{Fe} / \mathrm{MnO} @ \mathrm{C}$ core-shell structure embedded in amorphous carbon not only suppresses the agglomeration of magnetic particles and consequent skin effect, but also 
provides good chemical homogeneity and sufficient interfaces between $\mathrm{Fe} / \mathrm{MnO}$ nanoparticles and carbon. Besides, inescapable $\mathrm{Fe}_{3} \mathrm{C}$ accompanied by conventional reaction is suppressed in this method. On this basis, in corporation of magnetic metal with dielectric material, superb microwave absorption performance comes from efficient complementarities integrating permittivity with permeability. This study aims to develop convenient method to construct magnetic nanocrystals-carbon crystalline-amorphous structure high-performance microwave absorption. Moreover, it is to investigate the synergistic interaction between the magnetic nanocrystals and carbon matrix for practical applications in future.

\section{Experimental Procedures}

\subsection{Synthesis}

The porous amorphous carbon embedding crystalline $\mathrm{Fe} /$ $\mathrm{MnO} @ \mathrm{C}$ core-shell nanoparticles (FMCA) was prepared by an arc-discharged plasma technique. A compressed mixture of iron and manganese dioxide powders was attached to a water-cooled copper stage as the anode, and the carbon rod fixed on the opposite side served as the cathode. The chamber was evacuated to $\sim 10^{-3} \mathrm{~Pa}$, and then, the methane $\left(\mathrm{CH}_{4}\right)$ was introduced to be $0.2 \times 10^{-3} \mathrm{~Pa}$ as a gaseous source. The arc discharge was controlled simultaneously at $\sim 30 \mathrm{~V}$ and 90 A for 5-10 min by adjusting the distance between the two electrodes. The as-made FMCA nano-powders were collected after about $6 \mathrm{~h}$ and stored at ambient. The resultant FMCA were termed as FMCA-1, FMCA-2, FMCA-3, FMCA-4, FMCA-5, FMCA-6, and FMCA-7, corresponding to $\mathrm{Fe}$ mass ratios of $54 \%, 52 \%, 49 \%, 42 \%, 55 \%, 57 \%$, and $60 \%$, respectively.

\subsection{Characterization}

The crystal structure of the samples was studied by X-ray powder diffraction (XRD, SHIMADZU, XRD-6000) with $\mathrm{Cu} \mathrm{K} \alpha$ radiation, using an operation voltage and current of $40.0 \mathrm{kV}$ and $30.0 \mathrm{~mA}$, correspondingly. The scanning range was from the degree of $10^{\circ}$ to $80^{\circ}(2 \theta)$ and the scan speed was $4^{\circ} \mathrm{min}^{\mathrm{A}}$. Transmission electron microscope (TEM) images were obtained by JEOLJMF-2100F field emission transmission electron microscope at an accelerating voltage of $200 \mathrm{kV}$. The chemical bonding state of the nanocomposites was analyzed by X-ray photoelectron spectroscopy (XPS). The magnetic hysteresis loop was determined by Lake Shore vibrating sample magnetometer (VSM) with a magnetic field range of 17 KOe.

\subsection{Electromagnetic Measurement}

The relative complex permittivity and permeability versus frequency were obtained by coaxial reflection/transmission method using Agilent 8722ES vector network analyzer with the working frequency at $2-18 \mathrm{GHz}$. The cylindrical sample (with $3 \mathrm{~mm}$ in inner diameter, $7 \mathrm{~mm}$ in outer diameter and $2 \mathrm{~mm}$ in thickness) was fabricated by uniformly mixing paraffin matrix with $50 \mathrm{wt} \%$ absorbents. Then, the composite was pressed into cylindrical compacts. The transmission line theory was introduced to characterize the wave-absorbing properties, which is designated as reflection loss (RL).

\section{Results and Analysis}

\subsection{Structure and Phase Characterization}

The morphologies and structure are initially investigated by scanning electron microscope (SEM). All the samples display an aggregated yet microsphere-shaped morphology, as shown in Fig. 1a-d. The regular microspheres are uniform distribution. The element mapping reveals that $\mathrm{Fe}, \mathrm{Mn}$, $\mathrm{O}$, and $\mathrm{C}$ elements are uniformly distributed in FMCA-1 (Fig. 1e-i).

Microstructure of the samples is further observed by TEM. Figure $2 \mathrm{a}_{1}-\mathrm{d}_{1}$ shows spherical Fe/MnO@C nanocapsules embedded in the amorphous carbon. Obviously, two kinds of carbon with different morphology of graphite carbon and amorphous carbon are formed by arc-discharge method. An enlargement of the nanocomposite in Fig. $2 a_{2}-d_{2}$ reveals that amorphous carbon wraps on $\mathrm{Fe} /$ $\mathrm{MnO} @ \mathrm{C}$ nanocapsules forming a double-shell microstructure. The HRTEM image indicates that $\mathrm{Fe} / \mathrm{MnO}$ core is well coated by $\mathrm{C}$ shells. The embedded Fe/MnO@C nanocapsules are proved in very high degree of crystallinity. From Fig. $2 a_{3}-d_{3}$, the inter-plane distance between fringes of 0.25 , 0.23 , and $0.35 \mathrm{~nm}$, correspond to the (110) crystal plane of metallic $\mathrm{Fe},(200)$ plane of $\mathrm{MnO}$, and (002) plane of graphitic carbon, respectively. Lots of distorted lattices are 

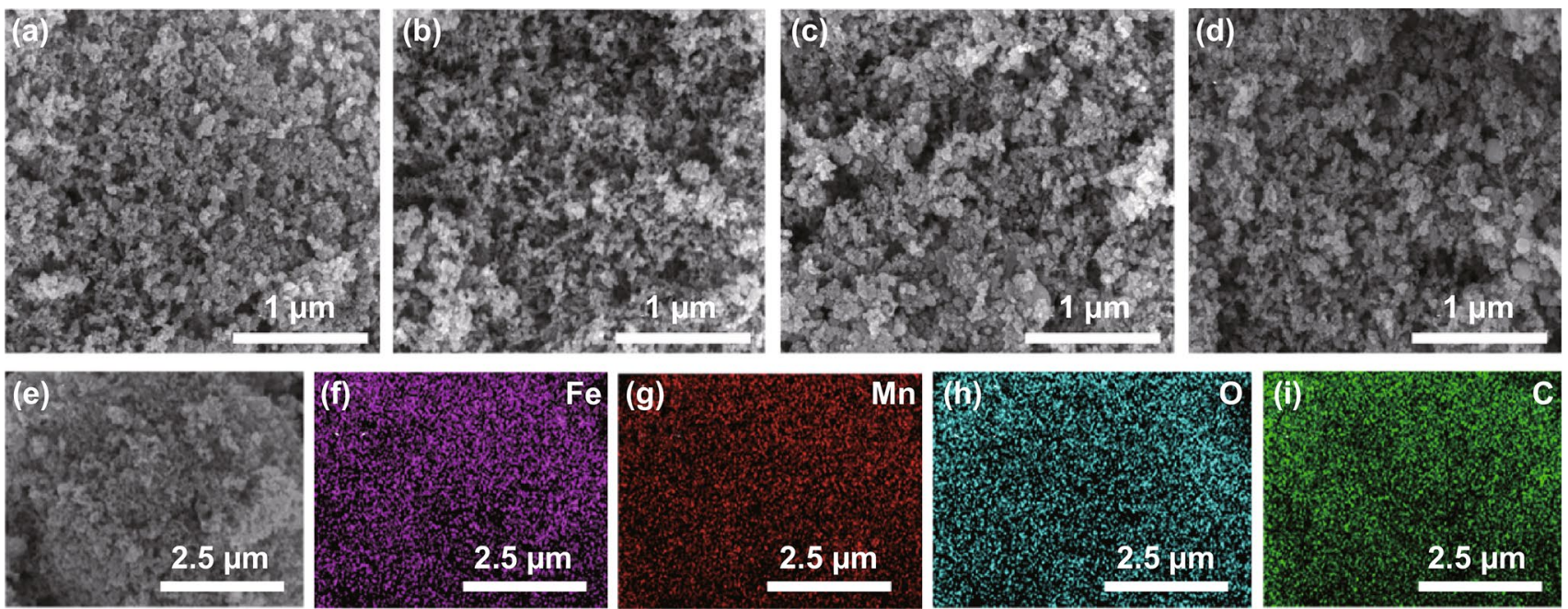

Fig. 1 SEM images of different samples: a FMCA-1, b FMCA-2, c FMCA-3, and d FMCA-4. e-i Elemental mapping images of FMCA-1

found on carbon-rich buffer layers. Some pronounced lattice defects, such as C-breakage and serious ripples, are present on the carbon layers, which mainly arise from the effect of energetic $\mathrm{Ar}^{+} / \mathrm{H}^{+}$ions of plasma and the fast quenching by means of energy exchange during reaction process. Additionally, the addition of $\mathrm{MnO}_{2}$ confines growth of the $\mathrm{Fe} /$ $\mathrm{MnO}$ nanocrystal. The average size of Fe/MnO@C nanocapsules is approximately below $50 \mathrm{~nm}$. Under the protection of carbon matrix, $\mathrm{Fe} / \mathrm{MnO}$ nanocrystals show distinct morphology and fine dispersion without severe agglomeration.

The electron energy loss spectroscopy (EELS) elemental mapping of FMCA composition shows that $\mathrm{Fe}, \mathrm{Mn}$, and $\mathrm{O}$ elements completely overlap due to the diffusion of $\mathrm{Fe}$ and $\mathrm{MnO}$ during the sample preparation process (Fig. S1). The well distribution of Fe nanoparticles in Fe/MnO@C nanocapsules ascribe to the isolation effect of $\mathrm{MnO}$ and confine effect of graphite carbon and amorphous carbon matrix. Besides, the crystalline graphite thicknesses of samples FMCA-1, FMCA-2, FMCA-3, and FMCA-4 are 11, 7, 3, and 2-3 layers, respectively. The graphite layers decrease with the reduction of $\mathrm{Fe}$ content while increasing $\mathrm{MnO}$ content, which further manifests that some of the amorphous carbon could be transformed into graphite by Fe catalysis graphitization process. The different graphite thickness indicates different amount of hetero-interface in the composition. But it is hard to definite the number. The morphology with multiple interfaces is helpful for multiple interfacial depolarization, interfacial scatterings, and diffuse scattering of microwave. For comparison, Fe@ C compositions are synthesized under the same condition without the addition of $\mathrm{MnO}_{2}$. In Fig. S2, the morphology of Fe@C compositions exhibits a reticulum-like porous structure, and Fe nanoparticles randomly distributes and encloses by the overlapped graphene nanosheets. High resolution TEM images in Fig. S2b illustrates the well-developed graphene layers with inter-plane spacing $0.36 \mathrm{~nm}$ wrapped on Fe nanoparticle, depicting the (110) crystal plane of metallic Fe phase with inter-plane spacing $0.25 \mathrm{~nm}$. There is no observation of amorphous carbon in the Fe@C compositions. The highly graphitization degree may be harmful for the microwave absorption. By contrast, $\mathrm{Fe}$ facilitates the crystallization of carbon during the reaction, whereas $\mathrm{MnO}$ reduces the crystallization of carbon and contributes to the formation of amorphous carbon in the reaction. Moreover, the elemental mapping of a single $\mathrm{Fe} / \mathrm{MnO} @ \mathrm{C}$ nanocapsules further manifests the distributions of $\mathrm{Fe}, \mathrm{Mn}, \mathrm{O}$, and $\mathrm{C}$ element with uniformly and dispersity (Fig. 2e-i). The nanocapsules tightly encapsulated by carbon matrix would facilitate the transfer of charge carriers between $\mathrm{Fe}, \mathrm{MnO}$, and $\mathrm{C}$, thus promoting excellent dielectric properties. Hence, this representative structure may contribute to electromagnetic attenuation.

The crystalline structure of the synthetic nanocomposites is measured by XRD analysis (Fig. 3a). The diffraction peaks of $44.7^{\circ}, 65.0^{\circ}$, and $82.3^{\circ}$ are indexed to (110), (200), and (211) crystal planes of cubic Fe (JCPDS No. 06-0696). Three diffraction peaks appear at $35.0^{\circ}, 40.7^{\circ}$, and $58.9^{\circ}$ can be indexed to (111), (200), and (220) planes, respectively, of the cubic MnO (JCPDS No. 75-0626). The 

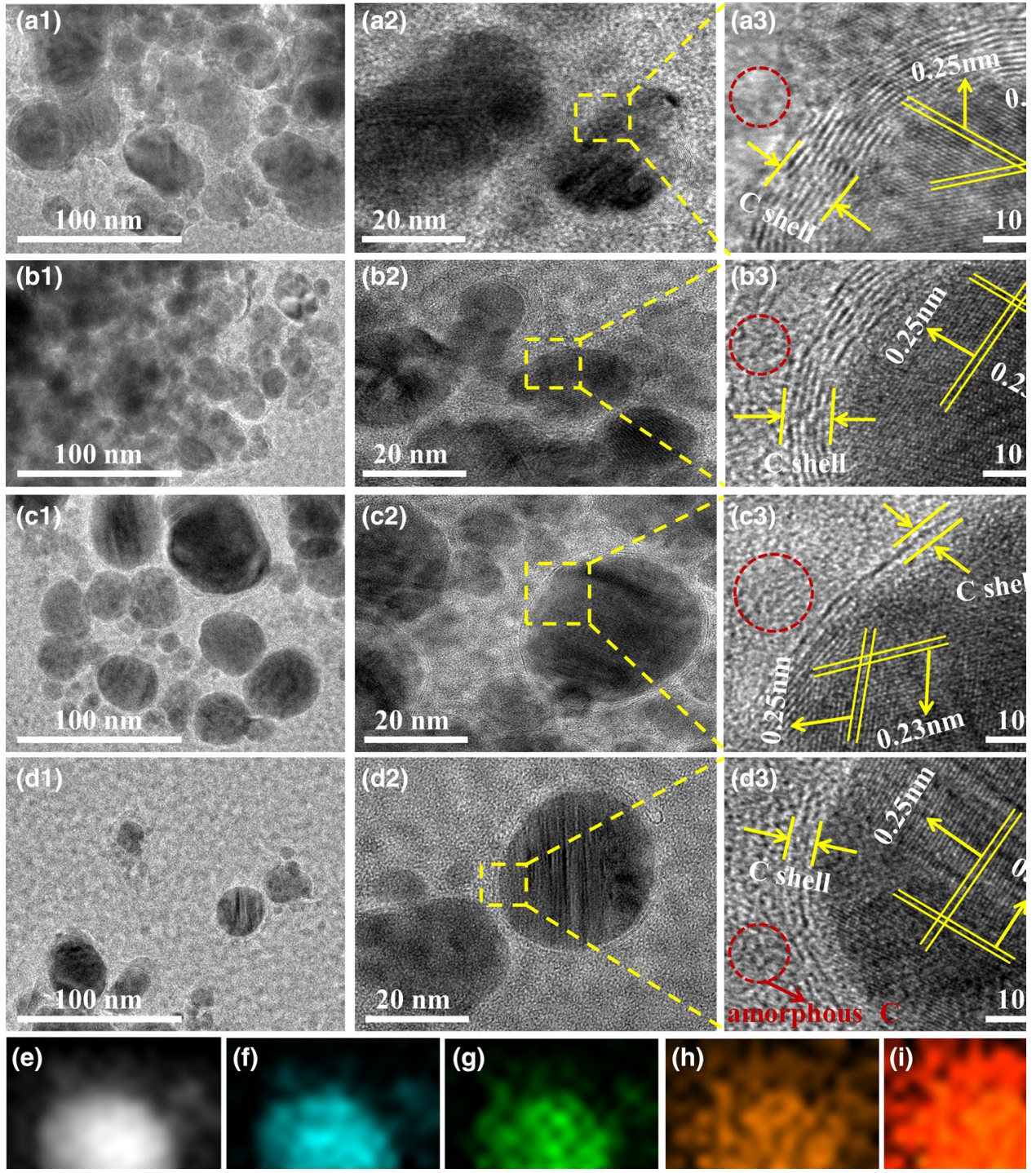

Fig. 2 TEM and high resolution TEM images: a1-a3 FMCA-1, b1-b3 FMCA-2, c1-c3 FMCA-3, and d1-d3 FMCA-4. HAADF-STEM images of $\mathbf{e}$ single $\mathrm{Fe} / \mathrm{MnO}$ nanocrystal and $\mathbf{f}-\mathbf{i}$ elemental mapping images

small hump is assigned to amorphous carbon, which indicates that the presence of $\mathrm{MnO}$ weaken the catalytic effect of iron species in the crystallization of carbon components [37]. The hierarchically porous structure of FMCA composition is further confirmed by nitrogen adsorption-desorption isotherms analysis. FMCA-3 reveals typical IV type curve, manifesting existence of amounts of mesopores (Fig. S3). This result, forming porous structure of crystalline Fe/MnO@C-amorphous carbon composition, is coordinated with that of TEM and XRD. The large specific surface area and porous structure benefit the improvement of impedance matching behavior and microwave attenuation [38-44]. The surface areas and pores is conducive to impedance of fillers and boosts microwave penetrating into materials, which is a competent way to broaden absorption bandwidth. Meanwhile, abundant pores in filler can generate multiply scattering of microwave because of extending the transmission path of incident electromagnetic wave. 

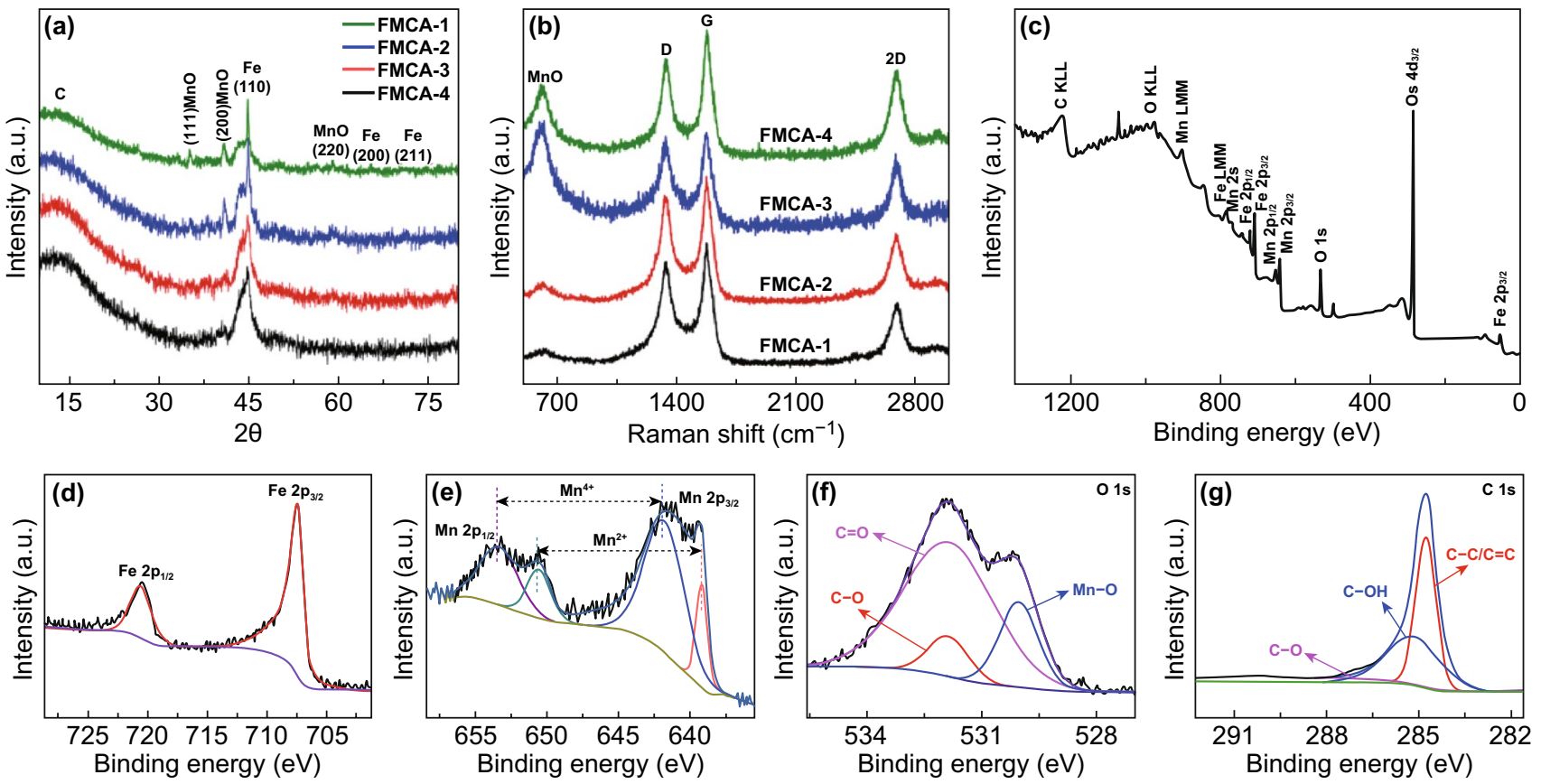

Fig. 3 a XRD patterns of FMCA. b Raman spectrum of FMCA-3. c survey XPS of FMCA-3. d Fe $2 p$, e Mn $2 p$, f O 1s, and g C 1s spectra of FMCA-3

In addition, the specific carbon content and iron content are ascertained by thermogravimetric (TG) analysis and $\mathrm{X}$-ray fluorescence spectroscopy in composites as shown in Fig. S4.

From the TEM images and XRD result aforementioned, graphitization degree of FMCA composite is low and bonding state of carbon atoms is observed differently. Meanwhile, Raman spectroscopy is used to identify the degree of graphitization in carbonaceous materials. In Fig. 3b, the prepared amorphous carbon embedded with dispersed Fe/MnO@C nanocapsules present two prominent peaks at around 1580 (D band) and $1348 \mathrm{~cm}^{-1}$ (G band). $\mathrm{G}$ band denotes the vibration of $s p^{2}$ hybridization, and $\mathrm{D}$ band denotes $s p^{3}$ defects and disorder, respectively [45]. In general, the bigger $I_{\mathrm{D}} / I_{\mathrm{G}}$ value (intensity ratio of $\mathrm{D}$ to $\mathrm{G}$ band) is, the higher degree of disorder signifies. The calculated values of $I_{\mathrm{D}} / I_{\mathrm{G}}$ for FMCA-1, FMCA-2, FMCA3 , and FMCA-4 are 0.86, 0.87, 0.97, and 0.81, respectively. Therefore, the $I_{\mathrm{D}} / I_{\mathrm{G}}$ FMCA-1, FMCA-2, FMCA3 , and FMCA-4 exhibits uptrend except FMCA-4, which ascribes to the increase in additive amount of $\mathrm{MnO}$ and decrease in carbon amount. When the dosage of $\mathrm{MnO}$ is gradually increased, relative content of amorphous carbon is further consolidated. And the content of $\mathrm{MnO}$ testifies uptrend as the intensity of peak at $621 \mathrm{~cm}^{-1}$ increasing. Additionally, 2D peak appears at $2689 \mathrm{~cm}^{-1}$ indicating several graphene layers in FMCA composition, which is in agreement with high resolution TEM images (Fig. 2). Note that, $I_{\mathrm{D}} / I_{\mathrm{G}}$ for FMCA-4 is obvious extraordinary from other samples. This is attributed to the low amount of carbon materials. The surface chemical composition and valence states are further performed by XPS.

As shown in Fig. 3c, the survey scan taken from FMCA-3 confirms the presence of $\mathrm{Fe}, \mathrm{Mn}, \mathrm{O}$, and $\mathrm{C}$ elements. From Fig. 3d, the peaks at $284.5,286.1$, and $289.0 \mathrm{eV}$ of $\mathrm{C} 1 \mathrm{~s}$ can be assigned to $\mathrm{C}-\mathrm{C} / \mathrm{C}=\mathrm{C}, \mathrm{C}=\mathrm{O}$, and $\mathrm{C}-\mathrm{OH}$ bonds, respectively [46]. In Fig. 3e, the $\mathrm{O} 1 \mathrm{~s}$ spectrum displays three peaks at 532.3, 530.8, and $529.2 \mathrm{eV}$, which ascribes to residual structure water $(\mathrm{H}-\mathrm{O}-\mathrm{H})$, hydrated manganese oxides $(\mathrm{Mn}-\mathrm{O}-\mathrm{H})$, and anhydrous manganese oxides ( $\mathrm{Mn}-\mathrm{O}-\mathrm{Mn})$, respectively. From Fig. 3f, the Fe $2 p$ spectrum exhibits two peaks at 684.0 and $686.1 \mathrm{eV}$, which correspond to the $\mathrm{Fe}$ $2 p_{3 / 2}$ and $\mathrm{Fe} 2 p_{1 / 2}$, respectively. Thus, the analysis results of XPS reveal the synthesis of metallic $\mathrm{Fe}$ in the sample. As shown in Fig. 3g, the fitted Mn $2 p$ spectra exhibit $\mathrm{Mn}^{2+}$, consistent with the results obtained from XRD.

In basics of structural characterization, the formation process for FMCA composition is well comprehended as 
shown in Fig. 4. There are three stages in forming process, i.e., the evaporation, nucleation/growth, and catalyzed graphitization. In the first stage, the raw materials of bulk $\mathrm{Fe}$ and $\mathrm{MnO}_{2}$, gaseous $\mathrm{CH}_{4}$ are completely co-evaporated by high-energy arc-plasma into gaseous atoms. In the second stage, the evaporated atoms of raw species will orderly undergo nucleation and growth. It depends on the melting points of $\mathrm{MnO}\left(1650{ }^{\circ} \mathrm{C}\right)$ and $\mathrm{Fe}\left(1600{ }^{\circ} \mathrm{C}\right)$. The $\mathrm{MnO}$ and $\mathrm{Fe}$ seeds will nucleate once achieving melting point. At the same time, the diffusion of $\mathrm{Fe}$ and $\mathrm{MnO}$ is companied with nucleation because of a very similar melting point. The $\mathrm{MnO}$ nanoparticle restricts the Fe cluster extensive grown and the particles are in nanometer-scale. The prepared Fe/ $\mathrm{MnO}$ nanocrystals exhibit their sphere-like morphologies and the amorphous carbon matrix make them protected from oxidization. Supersaturated carbon in the $\mathrm{Fe} / \mathrm{MnO}$ lattice undergoes fast quenching during escaping out of the central arc district to the water-cooled chamber wall. The saturated carbon atoms separate into the carbon matrix where considerable stress is produced in-plane with the carbon layers. At the last stage, amorphous carbon adjacent to $\mathrm{Fe} /$ $\mathrm{MnO}$ nanocrystal is converted to crystalline graphite due to catalysis of iron. On the one hand, the wrapped amorphous carbon matrix and the crystalline graphite are involved in the protection of $\mathrm{Fe}$ nanocrystal against oxidative damage. The normal stress concentrates at the largest convex curvature of the ellipsoid-like nanoparticles and creates serious deformation of the carbon layers. On the other hand, Fe nanoparticles are confined in the crystalline graphite and disperse uniformly with $\mathrm{MnO}$. The novel configuration can suppress the agglomeration of magnetic particles and consequent

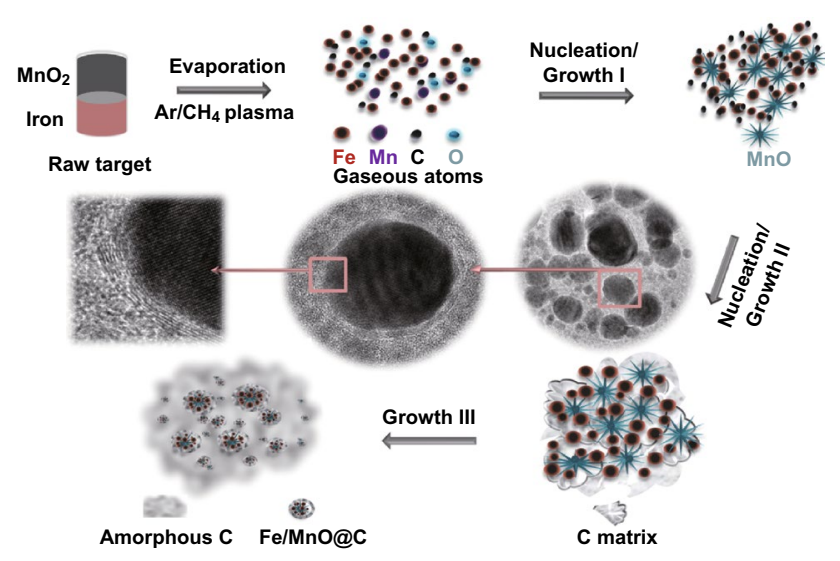

Fig. 4 Schematic diagram for formation of FMCA composition skin effect, and contribute good chemical homogeneity and sufficient interfaces between $\mathrm{Fe} / \mathrm{MnO}$ nanoparticles and $\mathrm{C}$. Besides, the addition of $\mathrm{MnO}$ avoids the formation of $\mathrm{Fe}_{3} \mathrm{C}$ in conventional iron-carbon compounds.

\subsection{Static Magnetization}

The electromagnetic wave absorption property is closely related to the magnetic performance. Theoretically, magnetic loss ability $\left(\mu^{\prime \prime}\right)$ is tightly related to magnetization value. As explained by the equation: $\mu^{\prime \prime}=(M / H) \sin \sigma$, where $M$ represents the magnetization, $H$ is the external magnetic field, $\sigma$ is the phase lag angle of magnetization behind external magnetic field. According to the equation, a higher magnetization value results in improvement of magnetic loss ability $\left(\mu^{\prime \prime}\right)$ value [47]. Figure 5a depicts the magnetic hysteresis loops of FMCA-1, FMCA-2, FMCA3, and FMCA-4. Obviously, the samples present typical ferromagnetic hysteresis behavior with saturation mag-

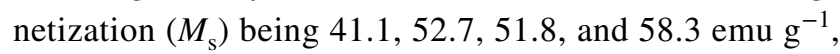
respectively, benefiting for the magnetic loss [48]. As is well known, the magnetic properties derive from coupling between electron spin and its orbital angular momentum [49]. Nanoparticles always show superparamagnetic properties due to magneto crystalline anisotropy, which is different from bulk materials. The magnetic particles in $\mathrm{Fe} / \mathrm{MnO}$ nanocrystals are deemed as single-domain particles with critical diameter (Dc) close to $20 \mathrm{~nm}$. The magnetic anisotropy energy is responsible for holding the magnetic moments along a certain direction, which is expressed as $E(\theta)=K_{\text {eff }} V \sin ^{2} \theta$, where $V$ donates volume of the particle, $K_{\text {eff }}$ is the anisotropy constant, and $\theta$ is the angle between the magnetization and the easy axis. The magnetization with two energetically easy directions is separated by the energy of barrier $K_{\text {eff }} V$. If the particle volume $V$ is extremely small, the thermal energy $\left(K_{\mathrm{B}} T\right)$ is sufficient to overcome the anisotropy barrier $\left(K_{\text {eff }} V\right)$ of the orientation of a well-isolated single-domain particle. When $K_{\mathrm{B}} T>K_{\text {eff }} V$, a single nanoparticle behaves like a giant paramagnet and is superparamagnetic. This can be the reason that the saturation magnetization of the samples presents uptrend even through the Fe content decrease. Furthermore, metal nanoparticles are easily oxidized, and value of $M s$ is high with minimizing ratio of oxidation. Meanwhile, the nanoparticle size is controlled to avoid 

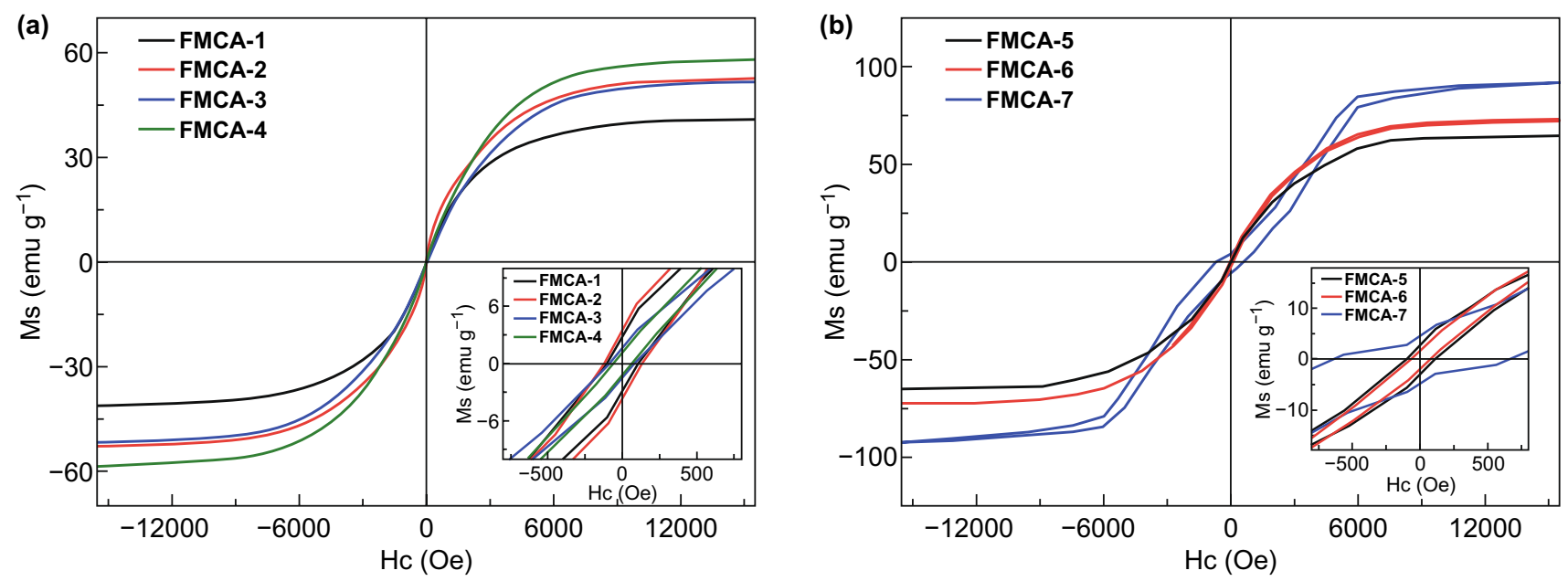

Fig. 5 a, b Magnetization hysteresis loops at $300 \mathrm{~K}$ and insert is the corresponding magnification around the origin

a reduction of $M s$ because of oxides and surface disorder [50]. Herein, the above problems can easily be overcome in this work. Since the crystalline Fe/MnO@C-amorphous carbon composition is subtly constructed to control the oxidation and the particle size xudong.wang@wisc.edu (Xudong Wang); caozq@dlut.edu.cn (Zhiqiang Cao); ymao@zzu.edu.cn (Yanchao Mao) while taking the advantage of different existing forms of graphite, which is easy to scale up and confine the sacrifices of magnetic loss. Moreover, by adjusting the $\mathrm{Fe}$ mass ratios to $60 \%$, a strong magnetization can be achieved as shown in Fig. 5b. The rationally designed FMCA composites reveal an excellent magnetic performance, which opens up a new path to restrict sacrifices of magnetic loss.

\subsection{Electromagnetic Parameters and Microwave Absorption Performance}

The electromagnetic wave absorption performance mainly depends on complex permittivity $\left(\varepsilon_{r}=\varepsilon^{\prime}-j \varepsilon^{\prime \prime}\right)$ and permeability $\left(\mu_{r}=\mu^{\prime}-j \mu^{\prime \prime}\right)[51,52]$. The complex permittivity for the Fe@C composition is shown in Fig. S5. Both $\varepsilon^{\prime}$ and $\varepsilon^{\prime \prime}$ decrease rapidly with adding $\mathrm{MnO}_{2}$ during the reaction as shown in Fig. 6a, b. Figure 6c, d displays the complex permeability. The $\mu^{\prime}$ value exhibits downtrend after the addition of MnO. Resonance peaks appear in the $\mu-f$ curves (Fig. 6c, d). Large values of $\varepsilon^{\prime}$ and $\varepsilon^{\prime \prime}$ endow strong attenuation capability (Fig. S6), which may lead to a poor impedance matching. The dielectric loss tangents $\left(\tan \delta_{\mathrm{e}}=\varepsilon^{\prime \prime} / \varepsilon^{\prime}\right)$ further exhibit that dielectric loss ability of theses composites. The order of dielectric loss ability is same as that of complex permittivity (Fig. 6e). The dielectric loss tangent also decreases with addition of $\mathrm{MnO}$. Compared with dielectric loss tangent, the value of magnetic loss tangent is small for FMCA samples (Fig. S7a). This is mainly put down to the introduction of nonmagnetic $\mathrm{MnO}$ and carbon matrix.

The dielectric loss, magnetic loss, and impedance matching determine collectively electromagnetic wave absorption performance [53]. The magnetic loss mainly comes from domain-well resonance, hysteresis loss, eddy current effect, natural and exchange resonance [54]. The domain-wall resonance is excluded from the $\mathrm{GHz}$ range. And the hysteresis loss is negligible in weak applied field [55]. When magnetic loss only originates from eddy current effect, $C_{0}=\mu^{\prime \prime}\left(\mu^{\prime}\right)^{-2} f^{-1}$ should tend to be a straight line. $C_{0}$ is fluctuant over $2-18 \mathrm{GHz}$ (Fig. S7b), it indicates that the natural resonance has also been devoted to the magnetic loss. The peaks around $7.3 \mathrm{GHz}$ are observed in Fig. 6c, which attributes to the natural resonances of the FMCA-1, FMCA-2, FMCA-3, and FMCA-4. $f_{\mathrm{r}}=2 \gamma K_{\text {eff }} / M_{\mathrm{s}}$ expresses frequency of natural resonance, where $K_{\text {eff }}$ donates the effective anisotropy constant, $\gamma$ the gyromagnetic ratio, and $M_{\mathrm{s}}$ the saturation magnetization [56]. The effective anisotropy constant relies on the size of particles and surface effect, given by $K_{\text {eff }}=K_{\mathrm{v}}+6 K_{\mathrm{s}} / R$, where $K_{\mathrm{v}}$ represents the volume anisotropy constant, $K_{\mathrm{s}}$ the surface anisotropy constant, and $R$ the radius of the nanoparticles [57]. $K_{\text {eff }}$ is enhanced with small size of the $\mathrm{Fe} /$ $\mathrm{MnO} @ \mathrm{C}$ nanocapsule due to the confinement effect. $M_{\mathrm{s}}$ of 

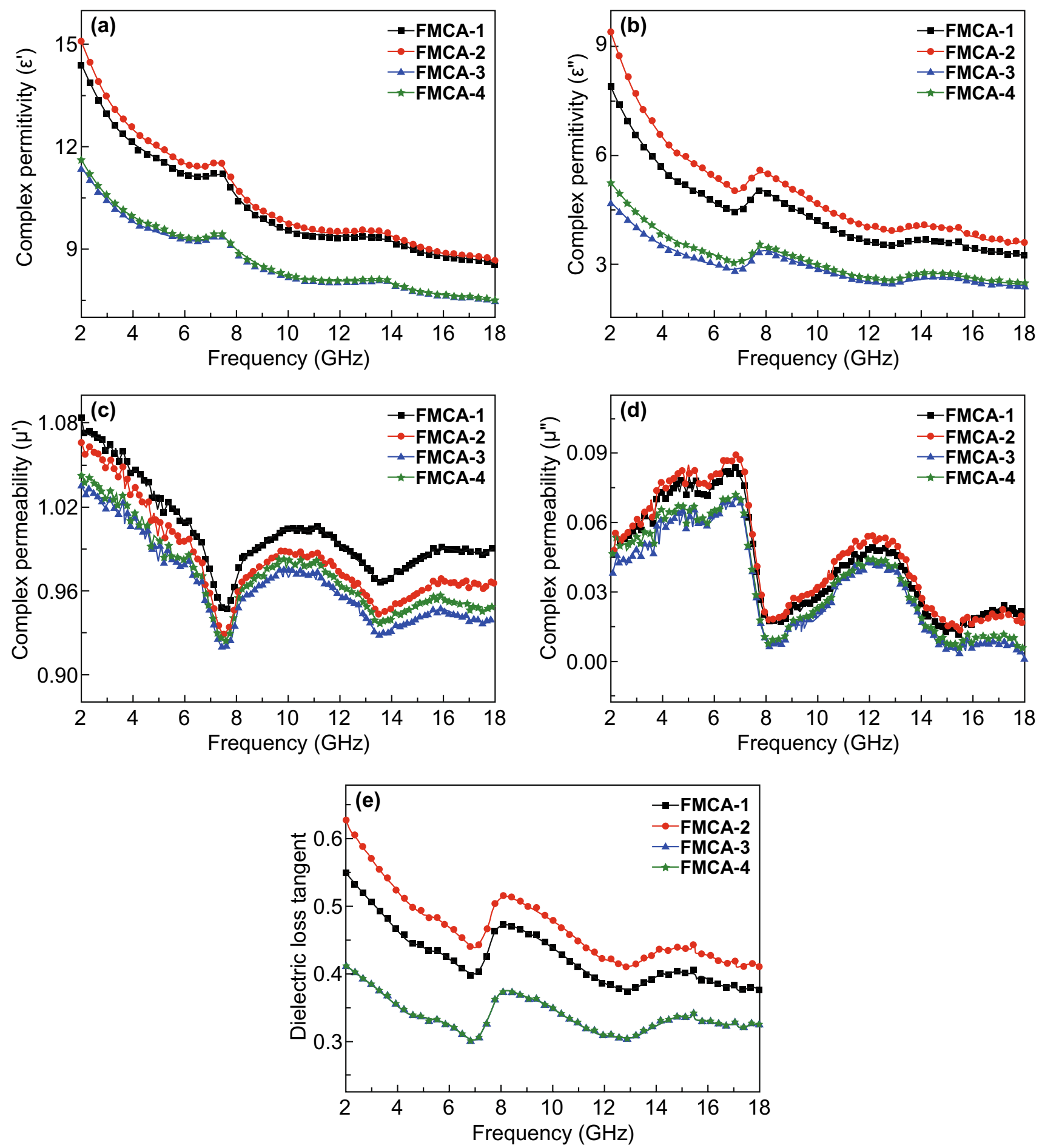

Fig. 6 Electromagnetic parameters of FMCA: a real part $\left(\varepsilon^{\prime}\right)$, b imaginary part $\left(\varepsilon^{\prime \prime}\right)$ of permittivity, $\mathbf{c}$ real part $\left(\mu^{\prime}\right)$, d imaginary part $\left(\mu^{\prime \prime}\right)$ of permeability, e dielectric loss tangent

the crystalline FMCA composition decreases as the introduction of nonmagnetic $\mathrm{MnO}$ compared to that of $\mathrm{Fe} @ \mathrm{C}$ composition. However, value of $M_{s}$ presents uptrend even through the decrease content of magnetic Fe. Hence, $f_{\mathrm{r}}$ appears in higher frequency of $7.3 \mathrm{GHz}$. Resonance peak around $13.6 \mathrm{GHz}$ ascribes to the exchange resonance since 
it has been well-documented to locate at high frequency $[58,59]$.

Generally, dielectric loss primarily derives from polarization and conductivity loss. And polarization loss includes dipolar polarization, interfacial polarization, ionic polarization, and electronic polarization. Ionic polarization and electronic polarization are excluded in microwave range because they appear at high frequency of $10^{3}-10^{6} \mathrm{GHz}$. Thus, the main dielectric attenuation mechanism is dipolar polarization and interfacial polarization. The dipolar polarization appears at molecule with obvious dipole moment. The interfacial polarization usually
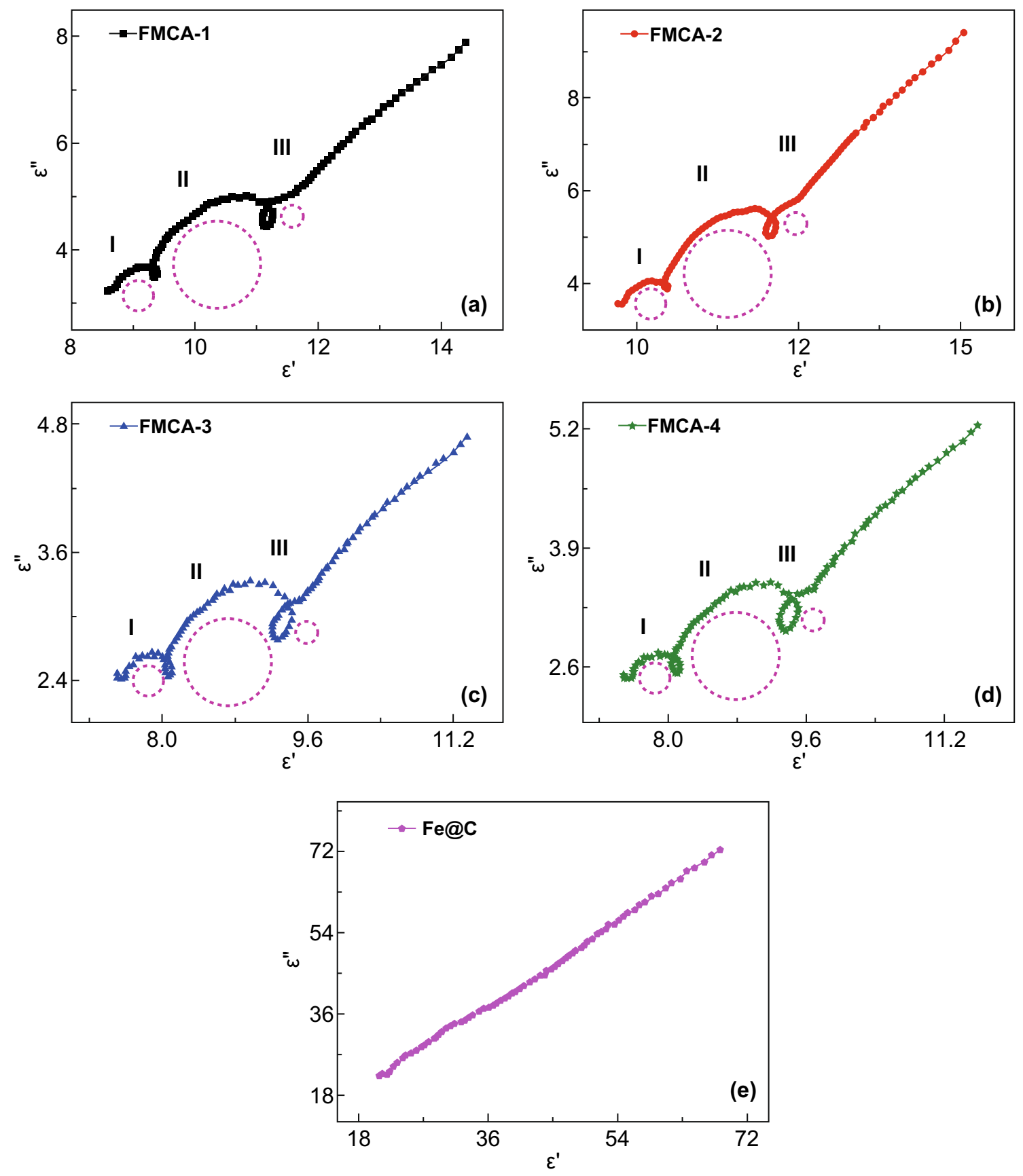

Fig. 7 Cole-Cole curves of a FMCA-1, b FMCA-2, c FMCA-3, d FMCA-4, and e Fe@C 
generates in a heterogeneous structure due to the accumulation and uneven distribution of space charges. The polarization process is investigated via Cole-Cole curves based on $\left.\left(\varepsilon^{\prime}-\left(\varepsilon_{\mathrm{s}}+\varepsilon_{\infty}\right) / 2\right)^{2}+\left(\varepsilon^{\prime \prime}\right)^{2}=\left(\left(\varepsilon_{\mathrm{s}}-\varepsilon_{\infty}\right) / 2\right)^{2}\right)[60]$.

The excessive dielectric loss of Fe@C composition leads to mismatched impedance due to formation of the

(a)
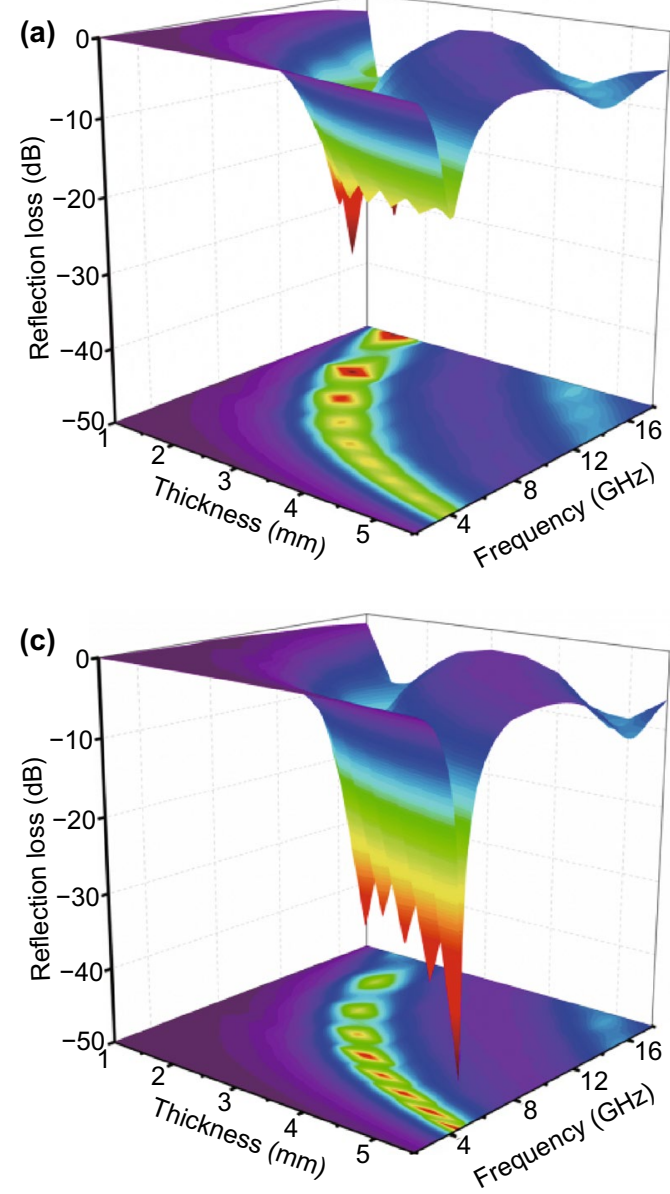

conductive $\mathrm{Fe}$ and graphite network. For respective Cole-Cole curves of FMCA-1, FMCA-2, FMCA-3, and FMCA-4 (Fig. 7), three semicircles are observed obviously, manifesting significant polarization in composites. The heterogeneous interface between $\mathrm{Fe} / \mathrm{MnO}$ nanocrystals and crystalline graphite, crystalline graphite, and
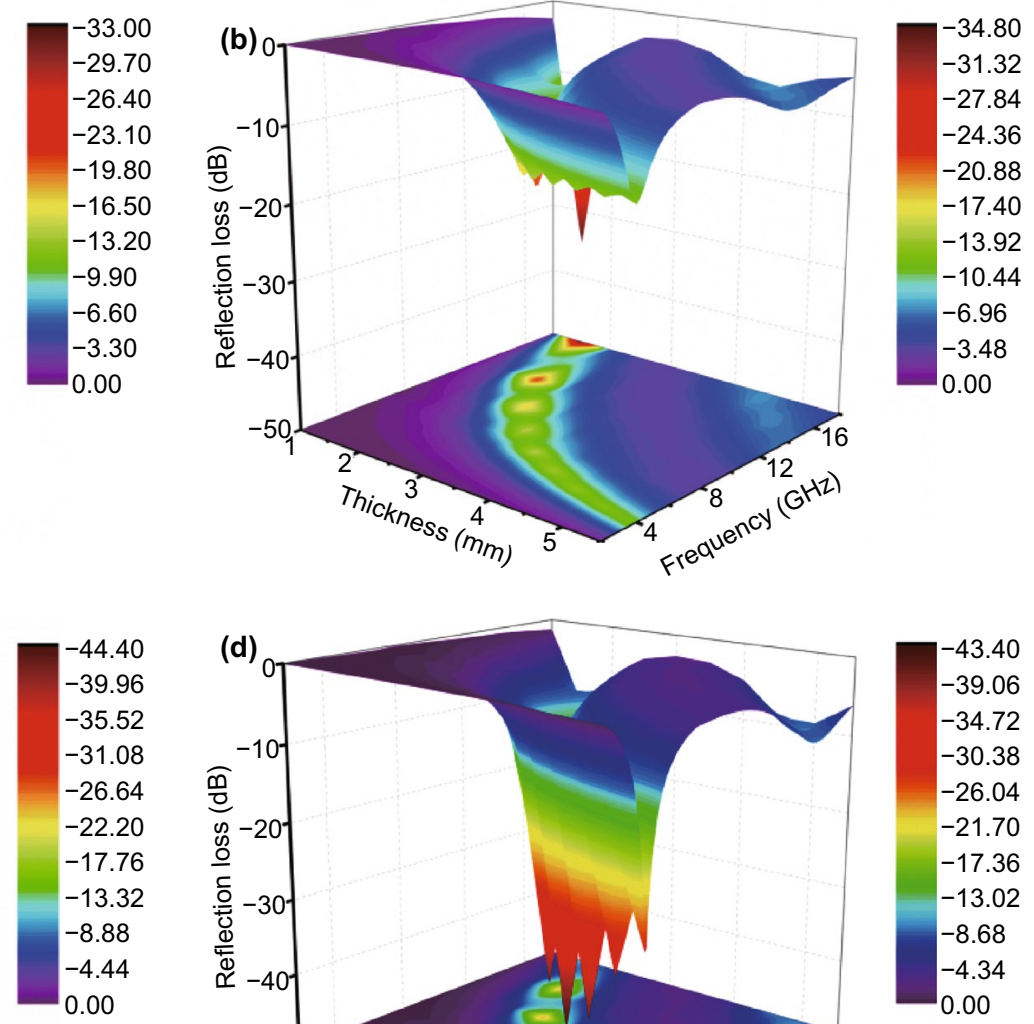

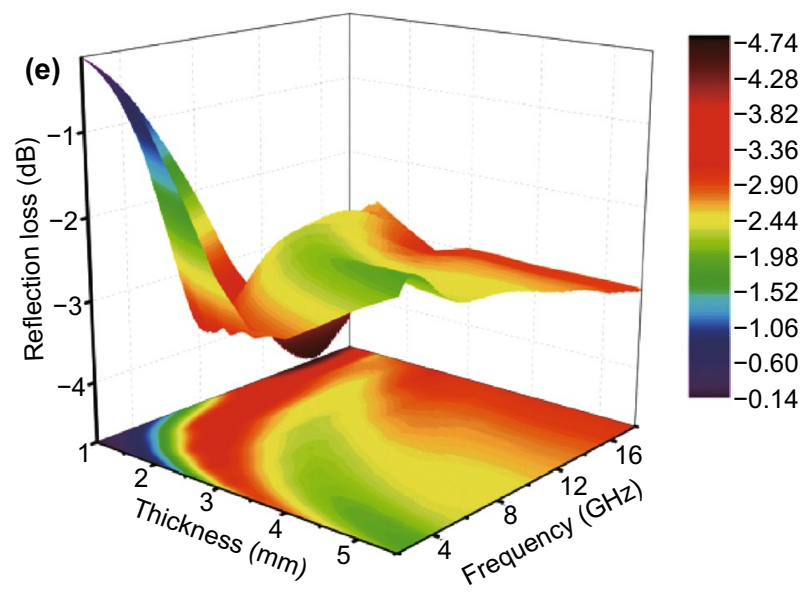

Fig. 8 Three-dimensional reflection loss maps of a FMCA-1, b FMCA-2, c FMCA-3, d FMCA-4, and e Fe@C over 2-18 GHz 
amorphous carbon endows multiple dielectric relaxation processes. But simultaneously, the Cole-Cole curves show long tail and semicircles distort somewhat. This indicates that the conductive loss also dominates in the dielectric loss. Introduction of $\mathrm{MnO}$ nanoparticles rationally can inhibit iron agglomeration and decrease conductivity, forming the homo-disperse of $\mathrm{Fe}$ and $\mathrm{MnO}$, and generate interface between carbon matrix and $\mathrm{Fe} / \mathrm{MnO}$ nanocrystal. For comparison, Cole-Cole curves plot is line and no
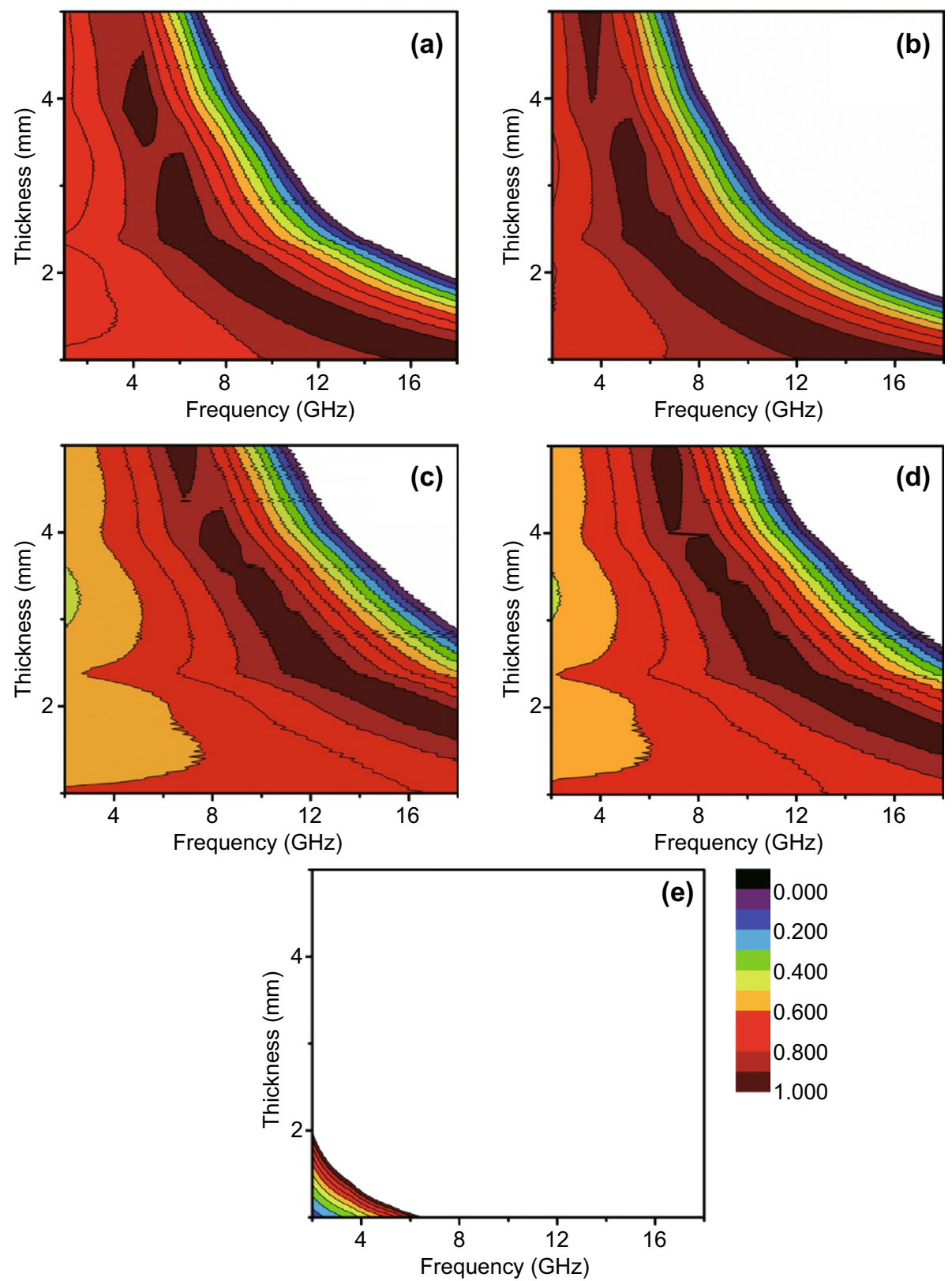

semicircles can be observed of the Fe@C composition (Fig. 7e). This reveals conduction loss dominates for dielectric loss for Fe@C composition. Thus, the FMCA composition interrupts the $\mathrm{Fe}$ and carbon conductive network. The dielectric loss decreases for FMCA-1, FMCA-2, FMCA-3, and FMCA-4 based on the free electron theory $[38,61]$.

RL of FMCA composition is calculated in basic of the complex permittivity and complex permeability (Fig. 8a-d).

Fig. 9 Impedance matching degree dependence of frequency of a FMCA-1, b FMCA-2, c FMCA-3, d FMCA-4, and e Fe@C 
Improved performance is achieved after addition of $\mathrm{MnO}$. The minimum reflection loss for FMCA-1 exhibits $-37.5 \mathrm{~dB}$ at $12.5 \mathrm{GHz}$ together with an effective absorbing bandwidth of $4.8 \mathrm{GHz}$ at a small absorber thickness of $2 \mathrm{~mm}$ (Fig. 8a). The FMCA-2 shows absorption property with minimum reflection loss of $-22.3 \mathrm{~dB}$ and an effective absorption bandwidth of $5.1 \mathrm{~dB}$ with thin thickness of $2 \mathrm{~mm}$ (Fig. 8b). With increased $\mathrm{MnO}_{2}$ content, the minimum reflection loss reaches $-45 \mathrm{~dB}$ with thickness of $5.5 \mathrm{~mm}$ for FMCA-3 and $4 \mathrm{~mm}$ for FMCA-4 (Fig. 8c, d). And the effective absorption bandwidth achieves $5.0 \mathrm{~dB}$ at thickness of $2 \mathrm{~mm}$. The minimum reflection loss value for Fe@ $\mathrm{C}$ composition is only $-5.6 \mathrm{~dB}$ due to the large dielectric loss (Fig. 8e).

Visibly, such excellent absorbing properties for FMCA-3 primarily ascribes to well impedance matching degree $\Delta$. In general, large integration area of $\Delta$ values below 1.0 of FMCA-3 demonstrates the better impedance matching in Fig. 9c. The reflection of electromagnetic wave is avoided at front surface of the absorbers [62,63]. $\alpha$ and $\Delta$ can be realized optimum balance in FMCA-3. Moreover, the FMCA compositions possess excellent impedance matching compared with that of Fe@C composition (Fig. 9e), revealing the microwave absorption capabilities of FMCA compositions can be controllable by regulating the addition of $\mathrm{MnO}_{2}$.

Overall, the outstanding microwave absorption performance of FMCA composites ascribes to the synergistic effect of dielectric loss and magnetic loss, derived from the interfacial polarization and moderate conductive loss of Fe and carbon matrix, along well with natural resonance and exchange resonance (Fig. 10). Firstly, dispersed MnO nanocrystals avoid agglomeration of Fe particles with small size, as shown in Fig. 2a, c. And the introduction of $\mathrm{MnO}$ decreases the degree of graphitization and fascinates the formation of amorphous carbon matrix. Then, the heterogeneous interfaces between $\mathrm{Fe} / \mathrm{MnO} /$ crystalline graphite/amorphous carbon matrix give rise to interfacial polarization and large amounts of defects formed, acting as polarized centers which combine to boost electromagnetic absorption performance. Secondly, uniformly dispersed $\mathrm{MnO}$ suppresses the stacking of graphene and agglomeration of magnetic particles, consequent restraining skin effect. Meanwhile, the impedance matching is well regulated. The well impedance matching guarantees electromagnetic wave entering the absorber. Inside the absorber, the multiple scattering and reflecting of microwave increase the propagation paths. This is benefit for

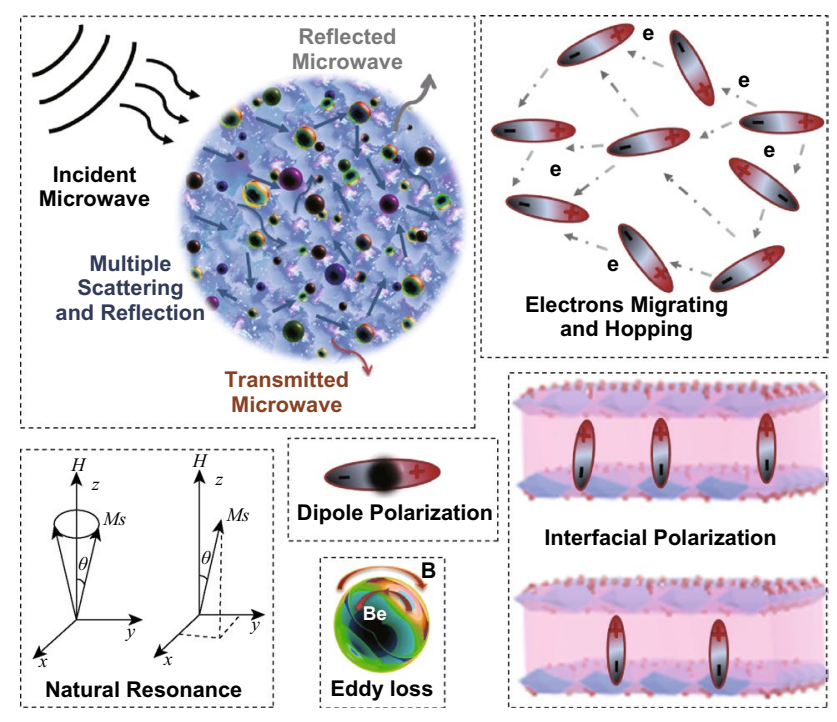

Fig. 10 Schematic illustrations for electromagnetic wave absorbing mechanism

the attenuation of microwave energy. Third, nanoscale Fe/ $\mathrm{MnO}$ nanocrystals in carbon matrix intensely response to broad-band microwave based on their induced currents. The electromagnetic energy can be converted to the thermal energy quickly [64].

\section{Conclusions}

The crystalline core-shell Fe/MnO@C nanocapsule inlaid in porous amorphous carbon is synthesized by modified arc-discharge method. The formed well-distributed $\mathrm{Fe} /$ $\mathrm{MnO}$ nanocrystals imped $\mathrm{Fe}$ aggregation and interruption of graphite conductive network due to introduction $\mathrm{MnO}$, resulting in tunable dielectric loss of the heterostructure. An increase in $\mathrm{MnO}$ brings about natural resonance in a specific frequency, multi-reflection at the interface of Fe and carbon, dielectric polarization, electron-jumping multi-phase envelop structure and size effect. Consequently, good impedance matching and strong attenuation capacity can be obtained because of the synergistic effect in the magnetic and dielectric loss. The optimal reflection loss achieves $-45 \mathrm{~dB}$ for FMCA-3, and effective absorption bandwidth achieves $5.0 \mathrm{~dB}$ with $2 \mathrm{~mm}$ thickness. This study not only provides insights on the design of advanced microwave absorbing materials with low density and broadband absorption, but also paves a versatile way for the large-scale synthesis of porous composites for extended applications. 
Acknowledgements The authors acknowledge the Supported by Program for the National Natural Science Foundation of China (Nos. 51577021 and U1704253), the Fundamental Research Funds for the Central Universities (DUT17GF107).

Open Access This article is licensed under a Creative Commons Attribution 4.0 International License, which permits use, sharing, adaptation, distribution and reproduction in any medium or format, as long as you give appropriate credit to the original author(s) and the source, provide a link to the Creative Commons licence, and indicate if changes were made. The images or other third party material in this article are included in the article's Creative Commons licence, unless indicated otherwise in a credit line to the material. If material is not included in the article's Creative Commons licence and your intended use is not permitted by statutory regulation or exceeds the permitted use, you will need to obtain permission directly from the copyright holder. To view a copy of this licence, visit http://creativecommons.org/licenses/by/4.0/

Electronic supplementary material The online version of this article (https://doi.org/10.1007/s40820-020-0388-4) contains supplementary material, which is available to authorized users.

\section{References}

1. X.P. Li, Z.M. Deng, Y. Li, H.B. Zhang, S. Zhao, Y. Zhang, X.Y. Wu, Z.Z. Yu, Controllable synthesis of hollow microspheres with Fe@Carbon dual-shells for broad bandwidth microwave absorption. Carbon 147, 172-181 (2019). https:// doi.org/10.1016/j.carbon.2019.02.073

2. D.Q. Zhang, T.T. Liu, J.Y. Cheng, Q. Cao, G.P. Zheng, S. Liang, H. Wang, M.S. Cao, Lightweight and high-performance microwave absorber based on $2 \mathrm{D} \mathrm{WS}_{2}-\mathrm{RGO}$ heterostructures. Nano-Micro Lett. 11(1), 38 (2019). https://doi.org/10.1007/ s40820-019-0270-4

3. Y. Song, L.H. He, X.F. Zhang, F. Liu, N. Tian, Y.S. Tang, J. Kong, Highly efficient electromagnetic wave absorbing metalfree and carbon-rich ceramics derived from hyperbranched polycarbosilazanes. J. Phys. Chem. C 121(44), 24774-24785 (2017). https://doi.org/10.1021/acs.jpcc.7b07646

4. D.W. Hu, J. Cao, W. Li, C. Zhang, T.L. Wu et al., Optically transparent broadband microwave absorption metamaterial by standing up closed ring resonators. Adv. Opt. Mater. 5(13), 1700109 (2017). https://doi.org/10.1002/adom.201700109

5. B. Zhao, X. Zhang, J.S. Deng, Z.Y. Bai, L.Y. Liang, Y. Li, R. Zhang, A novel sponge-like 2D Ni/derivative heterostructure to strengthen microwave absorption performance. Phys. Chem. Chem. Phys. 20(45), 28623-28633 (2018). https://doi. org/10.1039/C8CP06047A

6. X.F. Zhang, J.J. Guo, P.F. Guan, C.J. Liu, H. Huang et al., Catalytically active single-atom niobium in graphitic layers. Nat. Commun. 4, 1924 (2013). https://doi.org/10.1038/ncomm s2929
7. H. Sun, R.C. Che, X. You, Y.S. Jiang, Z.B. Yang et al., Cross stacking aligned carbon nanotube films to tune microwave absorption frequencies and increase absorption intensities. Adv. Mater. 26(48), 8120-8125 (2014). https://doi. org/10.1002/adma.201403735

8. H.L. Lv, Z.H. Yang, P.L. Wang, G.B. Ji, J.Z. Zheng, H.B. Zeng, Z.C. Xu, A voltage boosting strategy enabling a low frequency, flexible electromagnetic wave absorption device. Adv. Mater. 30(15), 1706343 (2018). https://doi.org/10.1002/ adma.201706343

9. X.M. Zhang, G.B. Ji, W. Liu, B. Quan, X.H. Liang, C.M. Shang, Y. Cheng, Y.W. Du, Thermal conversion of an $\mathrm{Fe}_{3} \mathrm{O}_{4} @$ metal-organic framework: a new method for an efficient $\mathrm{Fe}-\mathrm{Co} /$ nanoporous carbon microwave absorbing material. Nanoscale 7(30), 12932-12942 (2015). https://doi. org/10.1039/C5NR031

10. W. Zhou, L. Guo, Iron triad (Fe Co, Ni) nanomaterials: structural design, functionalization and their applications. Chem. Soc. Rev. 44(19), 6697-6707 (2015). https://doi.org/10.1039/ C5CS00033E

11. J. Guo, H.X. Song, H. Liu, C.J. Luo, Y.R. Ren et al., Polypyrrole-interface-functionalized nano-magnetite epoxy nanocomposites as electromagnetic wave absorbers with enhanced flame retardancy. J. Mater. Chem. C 5(22), 5334-5344 (2017). https://doi.org/10.1039/C7TC01502J

12. F. Qin, C. Brosseau, A review and analysis of microwave absorption in polymer composites filled with carbonaceous particles. J. Appl. Phys. 111(6), 4 (2012). https://doi. org/10.1063/1.3688435

13. H. Zhou, J.C. Wang, J.D. Zhuang, Q. Liu, A covalent route for efficient surface modification of ordered mesoporous carbon as high performance microwave absorbers. Nanoscale 5(24), 12502-12511 (2013). https://doi.org/10.1039/C3NR0 4379G

14. M.S. Cao, W.L. Song, Z.L. Hou, B. Wen, J. Yuan, The effects of temperature and frequency on the dielectric properties, electromagnetic interference shielding and microwave-absorption of short carbon fiber/silica composites. Carbon 48(3), 788-796 (2010). https://doi.org/10.1016/j.carbon.2009.10.028

15. H.L. Yu, T.S. Wang, B. Wen, M.M. Lu, Z. Xu et al., Graphene/polyaniline nanorod arrays: synthesis and excellent electromagnetic absorption properties. J. Mater. Chem. 22(40), 21679-21685 (2012). https://doi.org/10.1039/C2JM34273A

16. T.K. Gupta, B.P. Singh, S.R. Dhakate, V.N. Singh, R.B. Mathur, Improved nanoindentation and microwave shielding properties of modified MWCNT reinforced polyurethane composites. J. Mater. Chem. A 1(32), 9138-9149 (2013). https:// doi.org/10.1039/C3TA11611E

17. M.K. Han, X.W. Yin, L. Kong, M. Li, W.Y. Duan, L.T. Zhang, L.F. Cheng, Graphene-wrapped ZnO hollow spheres with enhanced electromagnetic wave absorption properties. J. Mater. Chem. A 2(39), 16403-16409 (2014). https://doi. org/10.1039/C4TA03033H

18. Y. Zhang, Y. Huang, T.F. Zhang, H.C. Chang, P.S. Xiao et al., Broadband and tunable high performance microwave absorption of an ultralight and highly compressible graphene 
foam. Adv. Mater. 27(12), 2049-2053 (2015). https://doi. org/10.1002/adma.201405788

19. B. Wen, M.S. Cao, M.M. Lu, W.Q. Cao, H.L. Shi et al., Reduced graphene oxides: light weight and high efficiency electromagnetic interference shielding at elevated temperatures. Adv. Mater. 26(21), 3484-3489 (2014). https://doi. org/10.1002/adma.201400108

20. W. Feng, Y.M. Wang, J.C. Chen, L. Wang, L.X. Guo et al., Reduced graphene oxide decorated with in situ growing $\mathrm{ZnO}$ nanocrystals: facile synthesis and enhanced microwave absorption properties. Carbon 108, 52-60 (2016). https://doi. org/10.1016/j.carbon.2016.06.084

21. C. Wang, X.J. Han, P. Xu, X.L. Zhang, Y.C. Du et al., The electromagnetic property of chemically reduced graphene oxide and its application as microwave absorbing material. Appl. Phys. Lett. 98(7), 072906 (2011). https://doi. org/10.1063/1.3555436

22. H.L. Xu, X.W. Yin, M. Zhu, M.K. Han, Z.X. Hou et al., Carbon hollow microspheres with a designable mesoporous shell for high-performance electromagnetic wave absorption. ACS Appl. Mater. Interfaces 9(7), 6332-6341 (2017). https://doi. org/10.1021/acsami.6b15826

23. R. Qiang, Y.C. Du, Y. Wang, N. Wang, C.H. Tian et al., Rational design of yolk-shell C@ C microspheres for the effective enhancement in microwave absorption. Carbon $\mathbf{9 8}$, 599-606 (2016). https://doi.org/10.1016/j.carbon.2015.11.054

24. C. Zhou, S. Geng, X.W. Xu, T.H. Wang, L.Q. Zhang et al., Lightweight hollow carbon nanospheres with tunable sizes towards enhancement in microwave absorption. Carbon 108, 234-241 (2016). https://doi.org/10.1016/j.carbon.2016.07.015

25. X.S. Qi, J.L. Xu, W. Zhong, Y.W. Du, Synthesis of high purity chain-like carbon nanospheres in ultrahigh yield, and their microwave absorption properties. RSC Adv. 5(21), 1601016016 (2015). https://doi.org/10.1039/C4RA09321F

26. S. Qiu, H.L. Lyu, J.R. Liu, N.N. Wu, W. Liu, Facile synthesis of porous nickel/carbon composite microspheres with enhanced electromagnetic wave absorption by magnetic and dielectric losses. ACS Appl. Mater. Interfaces 8(31), 2025820266 (2016). https://doi.org/10.1021/acsami.6b03159

27. Y.X. Li, R.G. Liu, X.Y. Pang, X.N. Zhao, Y.H. Zhang, G.W. Qin, X.F. Zhang, Fe@C nanocapsules with substitutional sulfur heteroatoms in graphitic shells for improving microwave absorption at gigahertz frequencies. Carbon 126, 372-381 (2018). https://doi.org/10.1016/j.carbon.2017.10.040

28. T. Wang, H.D. Wang, X. Chi, R. Li, J.B. Wang, Synthesis and microwave absorption properties of $\mathrm{Fe}-\mathrm{C}$ nanofibers by electrospinning with disperse Fe nanoparticles parceled by carbon. Carbon 74, 312-318 (2014). https://doi.org/10.1016/j. carbon.2014.03.037

29. X.C. Zhao, Z.M. Zhang, L.Y. Wang, K. Xi, Q.Q. Cao et al., Excellent microwave absorption property of graphene-coated Fe nanocomposites. Sci. Rep. 3, 3421 (2013). https://doi. org/10.1038/srep03421

30. G.M. Li, L.C. Wang, W.X. Li, Y. Xu, Mesoporous Fe/C and core-shell $\mathrm{Fe}-\mathrm{Fe}_{3} \mathrm{C} @ \mathrm{C}$ composites as efficient microwave absorbents. Microporous Mesoporous Mater. 211, 97-104 (2015). https://doi.org/10.1016/j.micromeso.2015.02.054

31. B. Zhong, C.J. Wang, G.W. Wen, Y.L. Yu, L. Xia, Facile fabrication of boron and nitrogen co-doped carbon@ $\mathrm{Fe}_{2} \mathrm{O}_{3} /$ $\mathrm{Fe}_{3} \mathrm{C} / \mathrm{Fe}$ nanoparticle decorated carbon nanotubes threedimensional structure with excellent microwave absorption properties. Compos. Part B 132, 141-150 (2018). https://doi. org/10.1016/j.compositesb.2017.09.001

32. Y.J. Qi, W.Z. Wang, X.G. Liu, G.M. Shi, Y. Qi, Nanocrystalline graphite embedded in carbonized hydrochars: an alternative matrix material for microwave absorption. Mater. Lett. 234, 249-252 (2019). https://doi.org/10.1016/j.matle t.2018.09.063

33. Y. Sun, J.W. Zhang, Y. Zong, X. Deng, H.Y. Zhao et al., crystalline-amorphous permalloy@ iron oxide core-shell nanoparticles decorated on graphene as high-efficiency, lightweight, and hydrophobic microwave absorbents. ACS Appl. Mater. Interfaces 11(6), 6374-6383 (2019). https://doi.org/10.1021/ acsami.8b 18875

34. S.S. Dai, B. Quan, X.H. Liang, J. Lu, Z.H. Yang, G.B. Ji, Y.W. Du, Excellent microwave response derived from the construction of dielectric-loss 1D nanostructure. Nanotechnology 29(19), 195603 (2018). https://doi.org/10.1088/1361-6528/ aab1c2

35. J. Mei, L. Zhang, Anchoring high-dispersed $\mathrm{MnO}_{2}$ nanowires on nitrogen doped graphene as electrode materials for supercapacitors. Electrochim. Acta 173, 338-344 (2015). https:// doi.org/10.1016/j.electacta.2015.05.064

36. N. Soin, S.C. Ray, S. Sarma, D. Mazumder, S. Sharma et al., Tuning the electronic and magnetic properties of nitrogen-functionalized few-layered graphene nanoflakes. J. Phys. Chem. C 121(26), 14073-14082 (2017). https://doi. org/10.1021/acs.jpcc.7b01645

37. S.P. Li, Y. Huang, D. Ling, N. Zhang, M. Zong, X.L. Qin, P.B. Liu, Enhanced microwave absorption with carbonencapsulated $\mathrm{Fe}-\mathrm{Co}$ particles on reduced graphene oxide nanosheets with nanoscale-holes in the basal plane. J. Colloid Interface Sci. 544, 188-197 (2019). https://doi.org/10.1016/j. jcis.2019.02.035

38. Y. Cheng, Z.Y. Li, Y. Li, S.S. Dai, G.B. Ji et al., Rationally regulating complex dielectric parameters of mesoporous carbon hollow spheres to carry out efficient microwave absorption. Carbon 127, 643-652 (2018). https://doi.org/10.1016/j. carbon.2017.11.055

39. J.R. Ma, X.X. Wang, W.Q. Cao, C. Han, H.J. Yang, J. Yuan, M.S. Cao, A facile fabrication and highly tunable microwave absorption of 3D flower-like $\mathrm{Co}_{3} \mathrm{O}_{4}$-rGO hybrid architectures. Chem. Eng. J. 339, 487-498 (2018). https://doi.org/10.1016/j. cej.2018.01.152

40. X.F. Liu, C.C. Hao, L.H. He, C. Yang, Y.B. Chen, C.B. Jiang, R.H. Yu, Yolk-shell structured Co-C/Void/ $\mathrm{Co}_{9} \mathrm{~S}_{8}$ composites with a tunable cavity for ultra-broadband and efficient lowfrequency microwave absorption. Nano Res. 11(8), 4169-4182 (2018). https://doi.org/10.1007/s12274-018-2006-Z

41. Z.C. Wu, W. Hu, T. Huang, P. Lan, K. Tian, F.F. Xie, L. Lei, Hierarchically porous carbons with controlled structures for 
efficient microwave absorption. J. Mater. Chem. C 6(32), 8839-8845 (2018). https://doi.org/10.1039/C8TC01813H

42. H.J. Wu, G.L. Wu, Y.Y. Ren, L. Yang, L.D. Wang, X.H. Li, $\mathrm{Co}^{2+} / \mathrm{Co}^{3+}$ ratio dependence of electromagnetic wave absorption in hierarchical $\mathrm{NiCo}_{2} \mathrm{O}_{4}-\mathrm{CoNiO}_{2}$ hybrids. J. Mater. Chem. C 3(29), 7677-7690 (2015). https://doi.org/10.1039/ C5TC01716E

43. P.B. Liu, Y.Q. Zhang, J. Yan, Y. Huang, L. Xia, Z.X. Guang, Synthesis of lightweight N-doped graphene foams with open reticular structure for high-efficiency electromagnetic wave absorption. Chem. Eng. J. 368, 285-298 (2019). https://doi. org/10.1016/j.cej.2019.02.193

44. Y. Cheng, Y. Zhao, H.Q. Zhao, H.L. Lu, X.D. Qi et al., Engineering morphology configurations of hierarchical flower-like $\mathrm{MoSe}_{2}$ spheres enable excellent low-frequency and selective microwave response properties. Chem. Eng. J. 372, 390-398 (2019). https://doi.org/10.1016/j.cej.2019.04.174

45. Q. Liao, M. He, Y.M. Zhou, S.X. Nie, Y.J. Wang et al., Highly cuboid-shaped hetero-bimetallic metal-organic frameworks derived from porous $\mathrm{Co} / \mathrm{ZnO} / \mathrm{C}$ microrods with improved electromagnetic wave absorption capabilities. ACS Appl. Mater. Interfaces 10(34), 29136-29144 (2018). https://doi.org/10.1021/acsami.8b09093

46. W. Feng, Y.M. Wang, J.C. Chen, B.Q. Li, L.X. Guo et al., Metal organic framework-derived CoZn alloy/N-doped porous carbon nanocomposites: tunable surface area and electromagnetic wave absorption properties. J. Mater. Chem. C 6(1), 10-18 (2018). https://doi.org/10.1039/C7TC03784H

47. C. Chen, S.Z. Bao, B.S. Zhang, Y. Chen, W. Chen, C.Y. Wang, Coupling $\mathrm{Fe} @ \mathrm{Fe}_{3} \mathrm{O}_{4}$ nanoparticles with multiplewalled carbon nanotubes with width band electromagnetic absorption performance. Appl. Surf. Sci. 467, 836-843 (2019). https://doi.org/10.1016/j.apsusc.2018.10.148

48. R.W. Shu, G.Y. Zhang, X. Wang, X. Gao, M. Wang et al., Fabrication of 3D net-like MWCNTs $/ \mathrm{ZnFe}_{2} \mathrm{O}_{4}$ hybrid composites as high-performance electromagnetic wave absorbers. Chem. Eng. J. 337, 242-255 (2018). https://doi. org/10.1016/j.cej.2017.12.106

49. W.M. Zhu, L. Wang, R. Zhao, J.W. Ren, G.Z. Lu, Y.Q. Wang, Electromagnetic and microwave-absorbing properties of magnetic nickel ferrite nanocrystals. Nanoscale 3(7), 2862-2864 (2011). https://doi.org/10.1039/C1NR10274E

50. T. Kim, J. Lee, K. Lee, B. Park, B.M. Juan, S.B. Lee, Magnetic and dispersible FeCoNi-graphene film produced without heat treatment for electromagnetic wave absorption. Chem. Eng. J. 361, 1182-1189 (2019). https://doi. org/10.1016/j.cej.2018.12.172

51. H.Q. Zhao, Y. Cheng, J.N. Ma, Y.N. Zhang, G.B. Ji, Y.W. Du, A sustainable route from biomass cotton to construct lightweight and high-performance microwave absorber. Chem. Eng. J. 339, 432-441 (2018). https://doi. org/10.1016/j.cej.2018.01.151

52. J. Feng, Y. Zong, Y. Sun, Y. Zhang, X. Yang et al., Optimization of porous $\mathrm{FeNi}_{3} / \mathrm{N}-\mathrm{GN}$ composites with superior microwave absorption performance. Chem. Eng. J. 345, 441-451 (2018). https://doi.org/10.1016/j.cej.2018.04.006
53. X.X. Wang, T. Ma, J.C. Shu, M.S. Cao, Confinedly tailoring $\mathrm{Fe}_{3} \mathrm{O}_{4}$ clusters-NG to tune electromagnetic parameters and microwave absorption with broadened bandwidth. Chem. Eng. J. 332, 321-330 (2018). https://doi.org/10.1016/j. cej.2017.09.101

54. B. Zhao, G. Shao, B.B. Fan, W.Y. Zhao, R. Zhang, Investigation of the electromagnetic absorption properties of $\mathrm{Ni@}$ $\mathrm{TiO}_{2}$ and $\mathrm{Ni} @ \mathrm{SiO}_{2}$ composite microspheres with core-shell structure. Phys. Chem. Chem. Phys. 17(4), 2531-2539 (2015). https://doi.org/10.1039/C4CP05031B

55. M.Z. Wu, Y.D. Zhang, S. Hui, T.D. Xiao, S. Ge et al., Microwave magnetic properties of $\mathrm{Co}_{50} /\left(\mathrm{SiO}_{2}\right)_{50}$ nanoparticles. Appl. Phys. Lett. 80(23), 4404-4406 (2002). https://doi. org/10.1063/1.1484248

56. F. Bødker, S. Mørup, S. Linderoth, Surface effects in metallic iron nanoparticles. Phys. Rev. Lett. 72(2), 282 (1994). https://doi.org/10.1103/PhysRevLett.72.282

57. M. Javid, Y.L. Zhou, D.X. Wang, D. Li, G.M. Shi et al., Magnetic behavior, electromagnetic multiresonances, and microwave absorption of the interfacial engineered Fe@ $\mathrm{FeSi} / \mathrm{SiO}_{2}$ nanocomposite. ACS Appl. Nano Mater. 1(3), 1309-1320 (2018). https://doi.org/10.1021/acsanm.8b00055

58. D.R. Li, B.S. Zhang, W. Liu, X.H. Liang, G.B. Ji, Tailoring the input impedance of $\mathrm{FeCo} / \mathrm{C}$ composites with efficient broadband absorption. Dalton Trans. 46(43), 14926-14933 (2017). https://doi.org/10.1039/C7DT02840G

59. L.J. Deng, P.H. Zhou, J.L. Xie, L. Zhang, Characterization and microwave resonance in nanocrystalline $\mathrm{FeCoNi}$ flake composite. J. Appl. Phys. 101(10), 103916 (2007). https:// doi.org/10.1063/1.2733610

60. W. Liu, Q.W. Shao, G.B. Ji, X.H. Liang, Y. Cheng, B. Quan, Y.W. Du, Metal-organic-frameworks derived porous carbonwrapped Ni composites with optimized impedance matching as excellent lightweight electromagnetic wave absorber. Chem. Eng. J. 313, 734-744 (2017). https://doi.org/10.1016/j. cej.2016.12.117

61. W. Liu, L. Liu, Z.H. Yang, J.J. Xu, Y.L. Hou, G.B. Ji, A versatile route toward the electromagnetic functionalization of metal-organic framework-derived three-dimensional nanoporous carbon composites. ACS Appl. Mater. Interfaces 10(10), 8965-8975 (2018). https://doi.org/10.1021/acsami.8b00320

62. L. Quan, F.X. Qin, D. Estevez, H. Wang, H.X. Peng, Magnetic graphene for microwave absorbing application: towards the lightest graphene-based absorber. Carbon 125, 630-639 (2017). https://doi.org/10.1016/j.carbon.2017.09.101

63. Y. Liu, Z. Chen, Y. Zhang, R. Feng, X. Chen, C.X. Xiong, L.J. Dong, Broadband and lightweight microwave absorber constructed by in situ growth of hierarchical $\mathrm{CoFe}_{2} \mathrm{O}_{4} /$ reduced graphene oxide porous nanocomposites. ACS Appl. Mater. Interfaces 10(16), 13860-13868 (2018). https://doi. org/10.1021/acsami.8b02137

64. F. Ye, Q. Song, Z.C. Zhang, W. Liu, S.Y. Zhang et al., Direct growth of edge rich graphene with tunable dielectric properties in porous $\mathrm{Si}_{3} \mathrm{~N}_{4}$ ceramic for broadband high performance microwave absorption. Adv. Funct. Mater. 28(17), 1707205 (2018). https://doi.org/10.1002/adfm.201707205 